\title{
Implication of Organizational Climate On Strengthening the Organisational Commitment
}

\author{
Besse Marhawati \\ Universitas Negeri Gorontalo \\ Corresponding e-mail: bessemarhawati@ung.ac.id
}

\begin{abstract}
The paper aims to describe the organization's climate implications in strengthening organization commitment. The paper described the result of study and review of literature from various articles related to organization climate and organization commitment then it identified, organized, and managed into presentation structure from the general scope to the specific scope. In addition, the paper is according to the existing presentation structure. The results of the discussion show that the organization's climate is based on the organization's climate diversity, namely: competitive climate, innovative climate, socio-moral climate, communication climate and service climate. The diversity of organization climate affects to the corporate productivity and the profits. When employees believe that their workplace supports ideas and change, and this requires initiatives of innovative resource, furthermore they are able to generate and express their innovative ideas and the change suggestions of the organization. It will be able to strengthen the commitment of employees in the organization to be higher.
\end{abstract}

Keywords: climate diversity, commitment, organization, innovation

\section{INTRODUCTION}

Achievement of organizational
objective is strongly influenced by the
individual commitment to support
organization's objective. On the other hand,
individuals also have high expectation on the
organization in achieving their personal
objectives. These conditions require
organization to be creative and innovative in
responding to the demand of its environment.
Therefore, organization is required to provide
conducive environment for every individual
because everyone have different
characteristics such as biographic
characteristics, different ability, different
personality, and different style in learning.
These characteristics support organization
differently. Therefore, organization should be
able to create various climate in order to gain
individual support and which finally will
strengthen the organizational commitment.
Climate means that employees in
organization develop their working
environment (Choi, 2007). Organizational
climate has direct implication on
environmental behavior because it features
relatively permanent perception on
organization which determine how they

operate within the organization. Whereas perception on organizational climate offers appropriate behavior in the given setting, when employees believe that their work place support their ideas and changes, and need initiative on innovative resources. Thus, they can produce and express their innovative ideas and give feedback for better changes.

On the other hand, commitment refers to the sense of ownership toward organization, hence, people will put all efforts to the achievement of their organization's objective. High level of dedication of the professional is usually due to their work commitment, their passion in their job, and their love for others and their love for money (Freidson in Jean, \& Kay, 2008). Individual commitment can be developed from positive psychological strength within the work environment. Positive organization attitude is certain positive approach with the implication to develop human resource and increase the management performance (Luthans, Norman, Avolio, \& Avey, 2008). 


\section{FINDINGS AND DISCUSSION}

\section{Organizational Climate}

Climate in organization level as studied by Ngo, Foley, \&Loy (2009), in their study on Family Friendly Work Practices (FFWPs) by testing the impact of family on jobs. It revealed that in organizational level, the support of top management on equal opportunity positively correlate with level of organization of FFWPs and organizational climate. In addition to positive correlation of organization climate and FFWPs, they also found that organizational climate also acts as mediator between FFWPs and level of organizational success. In addition, research conducted by Utama, Fletcher, Davis \& Germano (2008), who tested the multilevel model of work culture influence, family, and supportive work relationship on work disturbance on family. Their study revealed that the value of work culture in family support monitoring, work partner relationship, and work disturbance on family and highlight the need to implement multilevel model to understand this relationship. Conflict between work and family has important consequence on organization. Conflict between work and family has been related to organizational commitment, work satisfaction, willingness to switch work, reduce stress, and life satisfaction (Allen, Herst, Bruck, \& Sutton, 2000; Eby, Casper, Lockwood, Bordeaux, \& Brinley, 2005; Kossek \& Ozeki, 1998 in Utama, Fletcher, Davis \& Germano, 2008).

Other research related to organizational climate also conducted by Dysvik, A \& Kuvaas, B (2012), who studied the Perceived Supervisor Support (PSS) and Perceived Investment In Employee Development (PIED) and the performance of business unit. Their study revealed that the PSS climate has positive correlation with PIED climate and performance of business unit.

Other factors that influence the organizational climate are: the increase of employees' behavior and the effectiveness of work place intervention to increase the proenvironment behaviors (Unsworth, Dmitrieva, \& Adriasola, 2013); formal and informal interaction by Soda, \& Zaheer (2012), stated that consistency between formal and informal network give different impacts on performance; positive influence of work team by Walter \& Bruch (2008), these studies suggest positive work group simultaneously correlate in form of self-reinforcing spiral, which was supported by affective sharing and affective similarity among group members.

Climate variety has correlation with demographic category on organizational commitment, identification with organization, and attempt to quit. Gonzalez \& Denisi (2009) proposed that organizational variety has impact on the productivity and profit of the company. Further, Kaplan, Wiley, \& JR, Carl (2011), found that positive perception on organizational climate diversity correlates with the decrease of turnover and intention to support calculative attachment.

\section{Competitive Climate}

Competitiveness as individual attitude is defined as interpersonal satisfaction to compete and willingness to win and to be better than others ( (Hoautson, McIntire, kinnie, \& Terry in Fletcheri, Major\& Davis, 2008). Competitive attitude is individual variation which could also be environmental characteristic. Brown, Cron, \& Slocum in Fletcheri, Major,\& Davis (2008) introduced competitive psychological climate concept and was defined as the extent to which employee feels that organizational reward has to be based on the comparison of their performance against other performance.

Factors that contributed toward competitive climate include perception of different reward distribution, individual performance compared with fellow unit coworkers' performance, observation of others' competition, and status comparison. They also differentiate between psychological competitive climate (individual perception) and work group competitive climate (common perception among group members) and asses the result related to those types of climate (Kristof in Fletcheri, Major, \& Davis, 2008).

Fletcheri, Major, \& Davis (2008) studied the influence of competition as interaction between competitiveness and the attitude of competitive climate. Their study showed that the influence of competitive climate depends on the nature of the competitiveness and on the extent on which climates are assessed from the aspects of work satisfaction, organizational commitment, work dedication, and the level of performance on tasks assigned by the superior. In general, the 
impact of competitive individual climate is lower than the competitive attitude. Competitive psychological climate is related to bigger stress, regardless that competitive attitude indirectly correlated with task performance and self-assessment. The findings showed that manager has to be cautious in promoting the competitive climate.

\section{Innovative Climate}

Innovation is ideas acceptance and new processes for company and innovative activities within the limit of process and routine in the organization (Garcia \& Calantone in Zhou \& Wu, 2010).

Research by Leiponen and Helfat (2010), showed that wider horizon of innovation objectives and source of knowledge correlates with successful innovation. Further, innovation is called a success when the company seek wider knowledge in various technological and geographical domains (Ahuja and Lampert, 2001; Ahuja and Katila, 2004; Katila and Ahuja, 2002 in Leiponen and Helfat, 2010). In addition to investigating types and sources of new knowledge, the direction and the extent depend on company's research and development (R\&D).

The strength of innovative vision and mission can be predicted by using OCB (organizational citizenship behavior) which oriented on individual changes and multilevel process. These was due to two intervention variables namely, psychological empowerment and responsibility toward change. The result showed that changes in OCB were significantly influenced by organizational characteristics. Other researches result related to multilevel changes, such as group level phenomena which differentiated between the boundaries that influence the group result. In demographical boundaries (sex, age, and race) orients on relationship attributes and relationship conflicts which oriented on tasks attributes (Choi, \& S.Y., Thomas, 2010).

\section{Socio-Moral Culture}

Democratic organizational practices have been considering to promote the sociomoral climate in workplace, which in turn is expected to increase employees' orientation and community willingness to contribute for public betterment (Hoff, Lempert, \&Lappe,
1991; Kohlberg, Levine, \& Hewer, 1984; Lind \& Althof, 1992; Power, Higgins, \& Kohlberg, 1989 in Weber, Unterrainer, \&Schmid, 2009). Important condition for the establishment of socio-moral climate depends on the organization's vision and missions. For instance, in the case of school as a community, the socio-moral climates consisted of: (1) opportunity to discuss ethical issues and consideration to respect others' perspective; (2) participation in form of regulation, and (3) fair perception on available rules (Kohlberg et al in Weber, Unterrainer, \& Schmid, 2009).

Further, Lempert in Weber, Unterrainer, \& Schmid (2009), has broadened the socio-moral concept for industrial context and concluded that those rules will need five components: (1) workers' participation in social conflict of interest, rules, norms, and values; (2) strong reward, and monitoring, and support form supervisor and co-workers; (3) open and free communication, especially in legitimating values, norms, and company's principle, and (5) based on trust on tasks and responsibility allocation for others' welfare inside and outside the company's.

Weber, Unterrainer, \& Schmid (2009) studied the impact felt by the employees on democratic participation which oriented on pro-social behavior orientation, democratic values, commitment on company, and socio-moral climate perception. Findings showed that employees who democratically participate in organization's decision-making positively correlate with socio-moral climate of the company and their on organization and social behavior in the society. It also showed that socio-moral climate positively correlates with employees' commitment on organization. The influence of participation in organizational decision-making is partly mediated by socio-moral climate.

\section{Communication Climate}

Various researches have revealed the importance of communication and emphasized various factors that support organization identification (DiSanza \& Bullis, 1999; Riordan \& Weatherly, 1999; Scott, 1997) or commitment (Allen: 1992). Knowledges on how identification process influence communication are still few, however, the impact of communication initially and mostly studied through research 
on commitment (Schmids et al, 2001; Wiesenfeld, Raghuram, \& Garud, 1999 in Bartels, Pruyn, Jong, \& Joustra, 2007).

These studies discussed and revealed various positive correlations between various dimension of communication climate and organizational commitment (Guzley, 1992; Postmes, Tanis, \& De Wit, 2001; Trombetta \& Rogers, 1998 in Bartels, Pruyn, Jong, \& Joustra, 2007). Whereas studies on organization have revealed that communication climate and external prestige are felt as determiners to which extent employees can identify themselves with the organization as a whole (Smidts et al., 2001 in Bartels, Pruyn, Jong, \& Joustra, 2007). These studies investigated the influence of communication climate and external prestige perceived in identification with various level of organization.

Bartels, Pruyn, Jong, \& Joustra (2007) study revealed that communication climate has strong correlation with employees' identification related to identification of group weakness in daily tasks toward organization as a whole.

\section{Service Climate}

Linkage study has shaped the correlation between service climate and customers' satisfaction. Theoretical framework refer to climate service research stated that when organization has assigned appropriate focus on employees reward for customer service, customer will be more satisfied and the result will be more probable to go back to the organization. In particular, studies concluded that service climate theory showed that when employees showed their concern toward employees and customer, employees would be more likely to provide better service quality to the customer (Borucki \& Burke, 1999; Burke et al., 1992 in Towler, Lezotte, \& Burke, 2011). This theoretical model also refers to strategic human resource theory by stating that effective management policy practices will increase employees' performance (Ferris et al., 1998 in Towler, Lezotte, \& Burke, 2011).

Organization can show their concern to their employees effectively by considering to implement healthy and wise human resource practices, such as reward and human resource development systems to motivate employees to give their qualified services to customers (Towler, Lezotte, \& Burke, 2011).

Based on the description of this literature study it is found that organizational climate has implication on strengthening the organizational commitment. Organizational climate has direct implication on employees' behavior and is a mediator in increasing the company's profit (Ngo, Foley, \& Raymond, 2009). Conflict between job and family has important repercussion on organization (Allen, Herst, Bruck, \& Sutton, 2000; Eby, Casper, Lockwood, Bordeaux, \& Brinley, 2005; Kossek \& Ozeki, 1998 in Utama, Fletcher, Davis \& Germano, 2008). Consistency between formal and informal network has various effects on performance (Soda, \& Zaheer, 2012).

This literature study also showed that the variety of organizational climate has correlation with the demographic category in organizational commitment, organization identification, and intention to quit. Organizational climate strongly influenced organizational commitment especially in individual behavior for organizational changes.

\section{CONCLUSION}

Based on the discussion it can be concluded that variety of organizational climates, such as, competitive climate, innovative climate, socio-moral climate, communication climate, and service climate. This diversity of organizational climate can strengthen the organizational commitment, in this case the individual behavior for organizational changes.

Implication of organizational climate in strengthening the organizational commitment is evident in the diversity of climate, which can be created by organization. Organizational climate has direct implication on employees' behavior. Diversity of organizational climate has an impact on the productivity and the profit of organization. When employees believe that their workplace support their ideas and changes, and this need innovative resources, hence they can produce and express innovative ideas and recommendation for the betterment of organization. Thus, the employees' commitment will be higher. 
It is recommended that each organization to have ability to create conducive climate to understand their organization better hence, it can influence employees' behavior in achieving the objectives and goals of organization.

\section{REFERENCES}

Bartels, J., Pruyn, A., Jong, M.D, \& Joustra, I. 2007. Multiple Organizational Identification Levels And The Impact Of Perceived External Prestige And Communication Climate. Journal of Organizational Behavior. (online)), 28, 173-190, (www.interscience.wiley.com). Choi, J.N. 2007. Change-Oriented Organizational Citizenship Behavior: Effects Of Work Environment Characteristics And Intervening Psychological Processes. Journal of Organizational Behavior. (online), 28, 467484, (www.interscience.wiley.com).

Choi J.N, \& SY, Thomas. 2010. Group-Level Organizational Citizenship Behavior: Effects Of Demographic Faultline's And Conflict In Small Work Groups. Journal of Organizational Behavior. (online), 31, 10321054, (wileyonlinelibrary.com).

Dysvik, A, \& Kuvaas, B. 2102. Perceived Supervisor Support Climate, Perceived Investment In Employee Development Climate, And Business-Unit Performance. Human Resource Management. (online), Vol. 51, No. 5. Pp. 651-664, (wileyonlinelibrary.com).

Fletcher, T.D., Major, D.A, \& Davis, D.D. 2008. The Interactive Relationship Of Competitive Climate And Trait Competitiveness With workplace Attitudes, Stress, And Performance. Journal of Organizational Behavior. (online), 29, 899922, (www.interscience.wiley.com).

Gonzalez, J.A, \& Denisi, A.S. 2009. Crosslevel effects of demography and diversity climate on organizational attachment and firm effectiveness. Journal of Organizational Behavior. (online), 30, 21-40, (www.interscience.wiley.com).

Kaplan, D.M., Wiley, J.W, \& Maertz, C.P. 2011. The Role Of Calculative Attachment In The Relationship Between Diversity Climate And Retention. Human Resource Management. (online), Vol. 50, No. 2, Pp. 271 - 287, (wileyonlinelibrary.com).

Leiponen, A, \& Helfat, C.E. 2010. Research Notes And Commentaries Innovation
Objectives, Knowledge Sources, And The Benefits Of Breadth. Strategic Management Journal. (online), 31: 224236,(www.interscience.wiley.com).

Luthans, F., Norman, S.M., Avolio, B.J, \&Avey, J.B. 2008. The Mediating Role of Psychological In The Supportive Organizational Climate- Employee Performance Relationship. Journal of Organizational Behavior, (online), 29, 219238, (www.interscience.wiley.com).

Ngo, H.Y., Foley, S.F., \& Loi, R. 2009. Family friendly work practices, organizational climate, and firm performance: A study of multinational corporations in Hong Kong. Journal of Organizational Behavior. (online), 30 , 665-680,

(www.interscience.wiley.com).

Reid, E.M., \& Toffel, M.W. 2009. Responding To Public And Private Politics: Corporate Disclosure Of Climate Change Strategies. Strategic Management Journal. (online), 30:

$1157-$ 1178,(www.interscience.wiley.com).

Soda, G, \& Zaheer., A. 2012. A Network Perspective On Organizational Architecture: Performance Effects Of The Interplay Of Formal And Informal Organization. Strategic Management Journal. (online),33: 751-771, (wileyonlinelibrary.com).

Towler, A., Lazotte, D.V, \& Burke, M.J. 2011. The Service Climate-Firm Performance Chain: The Role Of Customer Retention. Human Resource Management. (online),Vol.50,No. 3, Pp. 391 - 406, (wileyonlinelibrary.com).

Tsai, W.C., Chi, N.W., Grandey, A.A, \& Fung, S.C. 2012. Positive Group Affective Tone And Team Creativity: Negative Group Affective Tone And Team Trust AsBoundary Conditions. Journal of Organizational Behavior. (online), 33, 638-656, (wileyonlinelibrary.com).

Unsworth, K.L., Dmitrieva, A., \&Adriasola, E. 2013. Changing Behavior: Increasing The Effectiveness Of Workplace Interventions In Creating Pro-Environmental Behavior Change. Journal of Organizational Behavior. (online), 34, 211-229, (wileyonlinelibrary.com).

Utama, D.A., Devis, D.D, \& Germano, L.M. 2008. The Influence Of Work-Family Culture And Workplace Relationships On Work Interference With Family: A Multilevel Model. Journal of Organizational Behavior. 
(online), 29, 881897,(www.interscience.wiley.com).

Wallace, J.E. \& Kay, F.M. 2008. The Professionalism of Practicing law: A Comparison Across Work Contexts. Journal of Organizational Behavior, (online), 29, 1021-1047,(www.interscience.wiley.com). Walter, F., \& Bruch, H. 2008. The Positive Group Affect Spiral: A Dynamic Model Of The Emergence Of Positive Affective Similarity In Work Groups. Journal ofOrganizational Behavior. (online), 29, 239261, (www.interscience.wiley.com).
Weber,W.G.,Unterriner, C., \& Schmid, B.E. 2009. The Influence Of Organizational Democracy On Employees' Socio-Moral Climate And Prosocial Behavioral Orientations. Journal of Organizational Behavior. (online), 30, 1127-1149, (www.interscience.wiley.com).

Zhou, K.Z, \& Wu, F. 2007. Technological Capability, Strategic Flexibility, And Product Innovation. Strategic Management Journal. (online), 31: 547-561, (www.interscience.wiley.com). 